\title{
EFFECT OF THE COMPOSITION AND AUTOCLAVE STERILIZATION OF DIETS FOR LABORATORY ANIMALS ON PELLET HARDNESS AND GROWTH PERFORMANCE OF MICE*
}

\author{
Marcin Barszcz ${ }^{1}$, Anna Tuśnio^, Marcin Taciak¹, Jolanta Paradziej-Łukowicz², Marek Molenda ${ }^{3}$, \\ Andrzej Morawski ${ }^{4}$
}

\author{
${ }^{1}$ Department of Monogastric Nutrition, The Kielanowski Institute of Animal Physiology and Nutrition, \\ Polish Academy of Sciences, Instytucka 3, 05-110 Jabłonna, Poland \\ ${ }^{2}$ Medical University of Gdańsk, Tri-City Animal Laboratory Research and Service Center, \\ Dębinki 1, 80-211 Gdańsk, Poland \\ ${ }^{3}$ Department of Physical and Technological Properties of Agricultural Materials, \\ Institute of Agrophysics, Polish Academy of Sciences, Doświadczalna 4, 20-290 Lublin, Poland \\ ${ }^{4}$ Feed Production Plant, Żurawia 19, 89-240 Kcynia, Poland \\ ‘Corresponding author: a.tusnio@ifzz.pan.pl
}

\begin{abstract}
The aim of the study was to determine the effect of modifications of ingredient composition and autoclaving of feeds for laboratory animals on pellet hardness and growth performance of mice. Composition of two breeding diets, containing either casein or soybean meal as the main protein sources, was modified by a change of wheat to maize proportions, or by oil and/or fibre supplementation (in casein containing diets only). The diets were pelleted and autoclaved at $121^{\circ} \mathrm{C}$ for 20 min. Pellet hardness of nonautoclaved soya diets was smaller than of casein diets except for those supplemented with oil. Oil supplementation tended to reduce or reduced pellet hardness of nonautoclaved but not of autoclaved diets whereas change of cereal proportion and type of fibre had no effect. Autoclaving increased pellet hardness of all diets, cancelled softening effect of oil supplementation of nonautoclaved casein diets and reduced difference between casein and soya containing diets. Pellet hardness was correlated with fat, fibre, starch, ash and phosphorus content. In mice, total consumption of autoclaved diets was greater than of nonautoclaved diets. Body weight was not affected by diet whereas it was decreased by autoclaving only in the 3rd and 6th week of experiment, the differences being of a very small magnitude. Growth of male mice depended on nutrient content, especially fibre, ash, phosphorus and energy, whereas body weight of females was highly correlated with phosphorus content. The dependencies differed between weeks of experiment.
\end{abstract}

Key words: laboratory animals, feed composition, autoclaving, pellet quality, growth performance

* Source of research financing: Work financed from the funds of the National Centre for Research and Development in Poland, project No. NR12 003506. 
Sterilization of stock diets for laboratory animals of specific pathogen free (SPF) status is indispensable. One of the significant methods of feed decontamination is autoclaving based on steam, pressure and heat treatment. Due to its availability, convenience and lower running costs, the autoclave sterilization method is broadly used in breeding units in spite of some negative influence on the nutritional value of the diets (Ford, 1976; Bielohuby et al., 2010). Our preliminary observations on the effects of autoclaving of two natural ingredient breeding diets have shown that this process results also in a considerable increase of pellet hardness which may depress feed intake and growth rate of young rodents. The pellet hardness of cereal based diets depended on the temperature and time of sterilization and was greater in feeds supplemented with casein than with soybean meal. However, soybean meal as the main protein source in the diet for laboratory animals, due to high content of phytoestrogens, may adversely affect hormonal status and distort results of the experiments (Brown and Setchell, 2001).

Among many factors affecting pellet quality, functional properties of dietary ingredients and changes of chemical components due to technological treatments are the most important (Wood, 1987; Thomas and van der Poel, 1996; Sørensen et al., 2009). The effects of starch (native versus gelatinized), sugar, protein (raw versus denatured) and solubility and resiliency of fibre determine hardness and durability of pellets which are considered as the most important physical parameters of pellet quality.

While factors influencing physical processes during pelleting and pellet characteristics have been extensively studied (Wood, 1987; Thomas and van der Poel, 1996; Thomas et al., 1997; Thomas et al., 1998; Aarseth et al., 2006), the effects of sterilization of previously pelleted feeds are not sufficiently recognized. In the present study, an attempt was undertaken to determine the effect of modifications of ingredient composition and autoclaving of feeds on pellet hardness and growth performance of mice.

\section{Material and methods}

\section{Diets}

Composition of basal and modified diets is presented in Table 1. Two basal diets differing in supplementary protein were prepared: the low-phytoestrogen soya-free diet contained casein (diet B) and the standard diet contained soybean meal (diet S) as the main protein sources. The modifications of both basal diets comprised the decreased wheat and increased maize proportions in the respective experimental diets $\mathrm{C}$ and SC. Additional modifications of $\mathrm{C}$ diet involved supplementation with oil (from 40 to $60 \mathrm{~g} / \mathrm{kg}$ ) and $/$ or with various fibre preparations $(50 \mathrm{~g} / \mathrm{kg})$. All fibre preparations, i.e. Vitacel (used in B and C diets) and Arbocel BWW40 and B600, were supplied by Rettenmaier \& Söhne GmbH (Germany). They were highly pure cellulose materials of average declared fibre thickness $20 \mu \mathrm{m}$ in both Arbocel preparations and fibre length $200 \mu \mathrm{m}$ and $60 \mu \mathrm{m}$ in Arbocel BWW40 and B600, respectively. In total, seven casein and two soya diets were prepared. 


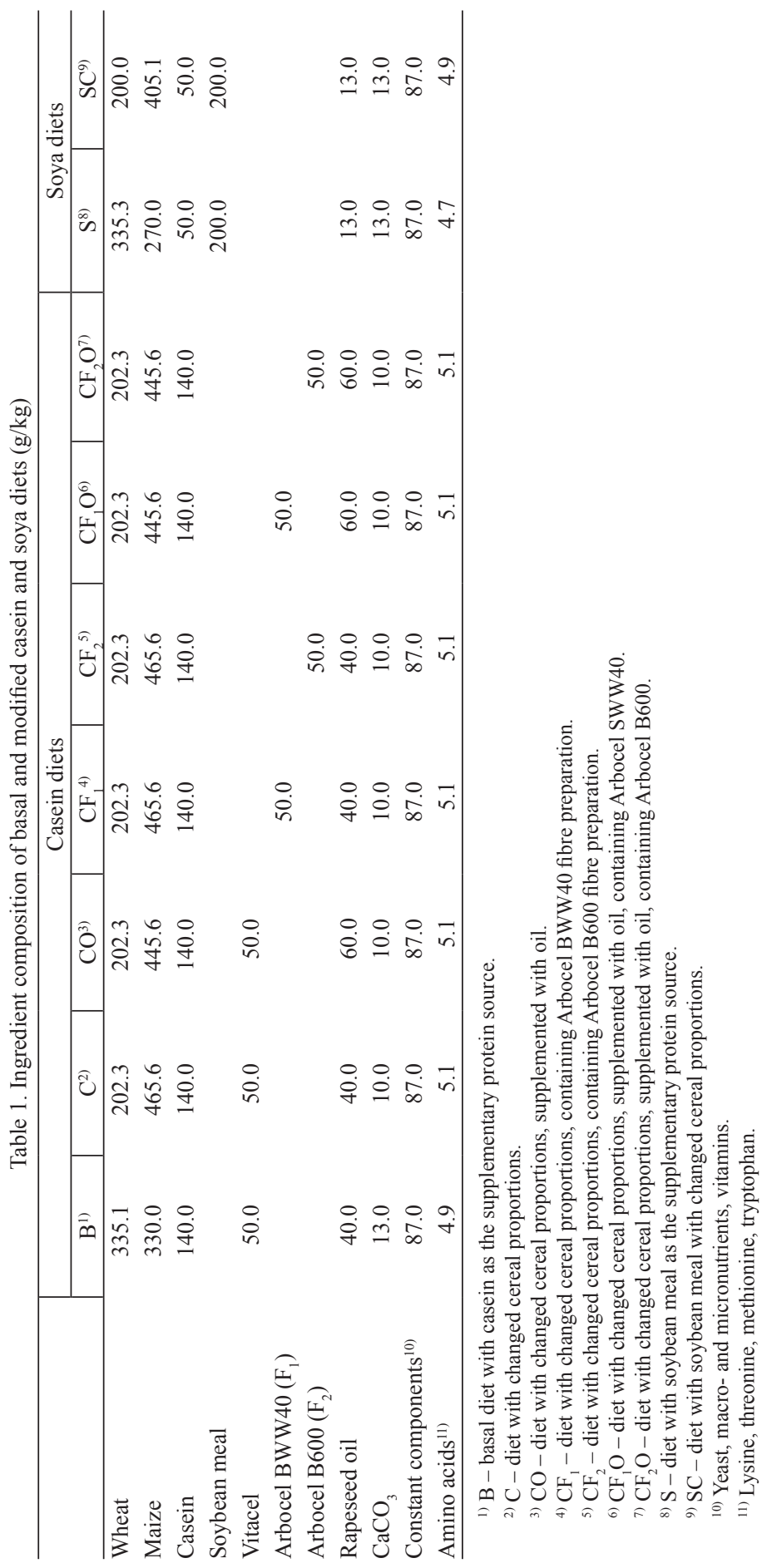


The diets were produced in the A. Morawski feed factory. The feeds were conditioned for about $60 \mathrm{~s}$ by overheated $\left(150^{\circ} \mathrm{C}\right)$ dry steam to the temperature $60-65^{\circ} \mathrm{C}$ and pelleted with the granulator G-O5 (IBMER, Poland) at $80-90^{\circ} \mathrm{C}$ on matrix holes. The diameter and thickness of matrix holes was 12 and $90 \mathrm{~mm}$, respectively. Pelleted diets were cooled and dried in ambient temperature for a few hours to $11-13 \%$ of moisture and then divided into two portions: one portion served as a nonautoclaved control and the second was packed into the perforated autoclavable paper bags and autoclaved in a steam autoclave STERIVAP SP HP 9612-2ED (BMT, Czech Republic) at $121^{\circ} \mathrm{C}$ for $20 \mathrm{~min}$. Efficiency of sterilization was checked using biological test SPORAL A.

\section{Measurements of pellet hardness}

Pellet hardness of both nonautoclaved and autoclaved diets was assessed one week after granulation as the tensile fracture stress measured using the diametralcompression test (Fell and Newton, 1970). The plane-faced disc specimen was compressed between platens of the testing machine (Lloyd LRX) and compressive force $\mathrm{P}$ was recorded until the sample was crushed. The velocity of compression was $2 \mathrm{~mm} / \mathrm{min}$. The fracture stress (maximum tensile stress) was calculated according to Fell and Newton (1970). Means and standard deviations of ten measurements for each treatment were calculated.

\section{Chemical analyses}

Dry matter, crude protein, ether extract, crude ash, crude fibre, total and phytic phosphorus, starch and sugars contents in diets were determined according to AOAC (2000). The gross energy of diets was measured in a Parr adiabatic oxygen bomb calorimeter (KL-10, Precyzja, Poland).

\section{Mice experiment}

The effects of diet formulation and autoclaving on feed intake and growth rate were studied on 2165 -week-old BALB/cAnNCrl mice of SPF status. Health status was confirmed according to recommendations of the Federation of European Laboratory Animal Science Associations (Nicklas et al., 2002). The experiment was approved by the Third Local Ethical Commission in Warsaw (resolution No. 55/2008). Animals were housed in proper cages for mice with filters in an environment that maintains constant conditions of temperature $\left(22 \pm 2^{\circ} \mathrm{C}\right)$, humidity $(55 \pm 10 \%)$, lighting $(12 \mathrm{~h} / 12 \mathrm{~h}$ light/dark cycle) with air exchanged 12 times or more per hour. The mice were sacrificed in a special unit for rodent euthanasia $\left(\mathrm{CO}_{2}\right.$-Box model THF3386, Ehret GmbH, Germany) by inhalation of a mixture of carbon dioxide and oxygen.

The mice were divided into 18 groups, each comprising six males and six females. Males and females were maintained separately in collective polypropylene cages, six mice per cage, and fed ad libitum during 6 weeks on the nonautoclaved and autoclaved experimental diets. Collective feed intake per cage was registered daily whereas body weight was recorded individually every week. 


\section{Statistics}

Statistical evaluation of pellet hardness was performed according to two factorial analysis of variance with $2 \times 9$ arrangement for main effects of autoclaving and diet, with 10 replicates per treatment. Statistical evaluation of body weight of mice in the consecutive weeks followed a block design with a factorial arrangement of $2 \times 2 \times 9$ for main effects of animal gender, autoclave sterilization and diet, with 6 replicates per treatment. Data are presented as means and their standard error values. The effects of experimental factors and their interactions were determined by three-way ANOVA and differences between treatments were analysed post hoc by Tukey HSD test. In order to describe the relationship between nutrient components of diets (crude protein, ether extract, crude ash, crude fibre, total and phytic phosphorus, starch, sugars) and mice growth parameters or pellet hardness multiple regression analysis was performed. To simplify the model all independent variables with P-value higher or equal to 0.05 were removed from equation. All statistical analyses were done using STATGRAPHICS Centurion XVI ver. 16.1.03 (Statistical Graphic Corp., 1982-2010) statistical package.

\section{Results}

Chemical composition of experimental diets is given in Table 2. Gross energy content ranged from 1.88 to $2.00 \mathrm{MJ} / \mathrm{kg} \mathrm{DM}$ and crude protein content approximated $22 \%$ of DM. The greatest variation was in fat and fibre content and autoclave sterilization seems to decrease fat and increase fibre content. The differences in crude ash, total and phytic phosphorus content were of small magnitude. Sugars content ranged from 3.26 to 4.89 and was slightly lower in autoclaved than in nonautoclaved diets. Starch content also differed between experimental diets, but autoclaving seems to not affect this parameter.

Modifications of the ingredient composition affected pellet hardness to a small extent (Table 3). Neither change of wheat to maize proportions ( $\mathrm{B}$ vs $\mathrm{C}$ diet) nor the type of fibre preparation $\left(\mathrm{C}\right.$ vs $\left.\mathrm{CF}_{1} \mathrm{vs}_{\mathrm{CF}_{2}}\right)$ or increase of oil content affected pellet hardness of nonautoclaved casein diets, except diet $\mathrm{CF}_{2} \mathrm{O}$ which was significantly softer than $\mathrm{CF}_{2}, \mathrm{CF}_{1}$ and $\mathrm{C}$ diets. However, a tendency to a lower pellet hardness in all diets supplemented with oil was evident. Also soya diets, both basal and with changed cereal proportion, were significantly softer than the respective casein diets ( $\mathrm{S}$ vs $\mathrm{B}$ and $\mathrm{SC}$ vs $\mathrm{C}$ ) while they did not differ between themselves.

Pellet hardness of all diets was considerably increased by autoclaving and was not greatly affected by dietary modifications. A tendency to a greater hardness of diets supplemented with two types of Arbocel fibre than Vitacel ( $\mathrm{CF}_{1}$ and $\mathrm{CF}_{2}$ vs $\left.\mathrm{C}\right)$, not observed in nonautoclaved diets, as well as a softening effect of oil in diets $\mathrm{CO}$ and $\mathrm{CF}_{2} \mathrm{O}$, were not statistically confirmed. A tendency to a smaller pellet hardness of both soya diets than casein diets was statistically confirmed as the difference between these soya diets and $\mathrm{CF}_{2}$ diet. 


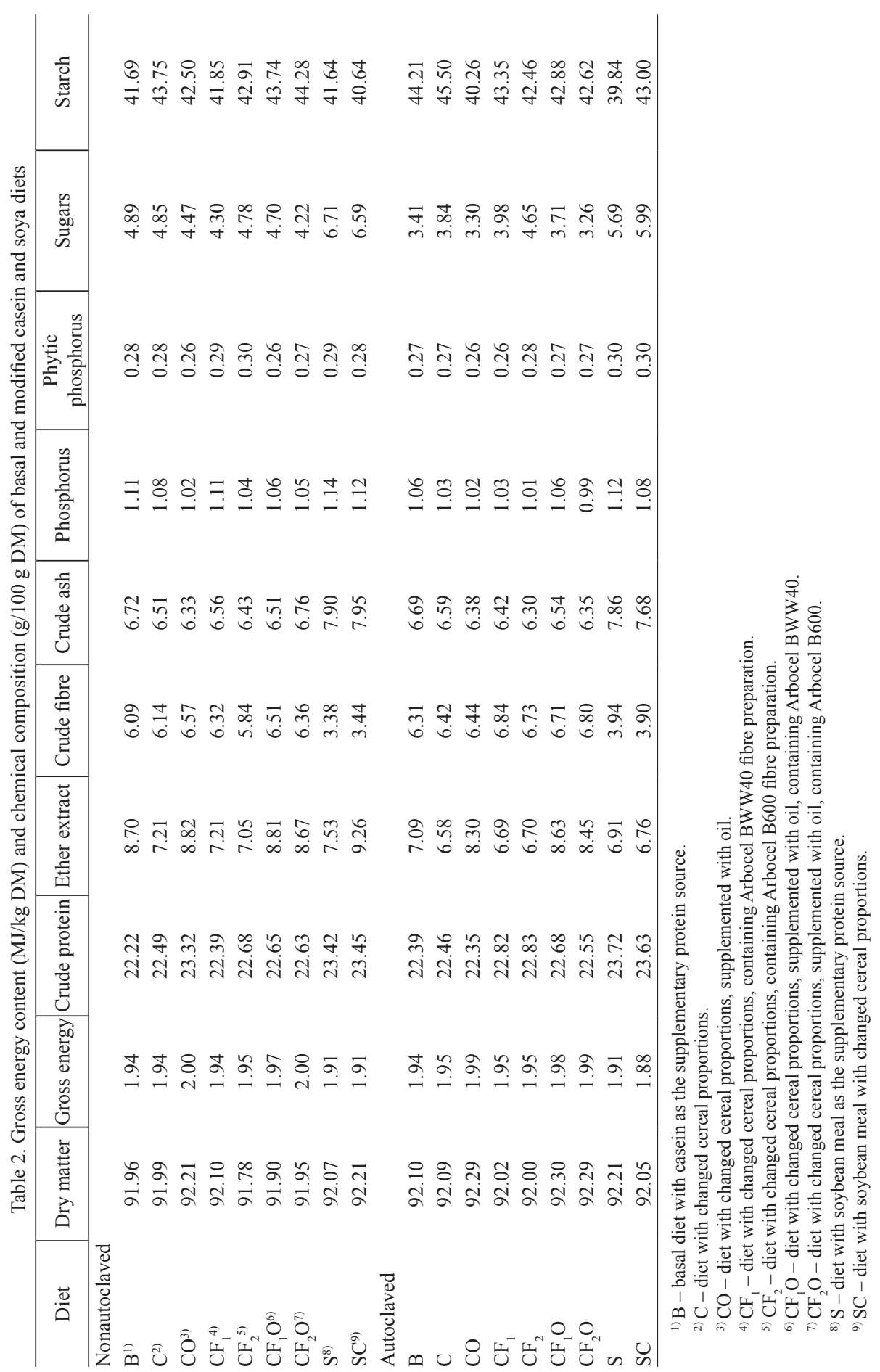




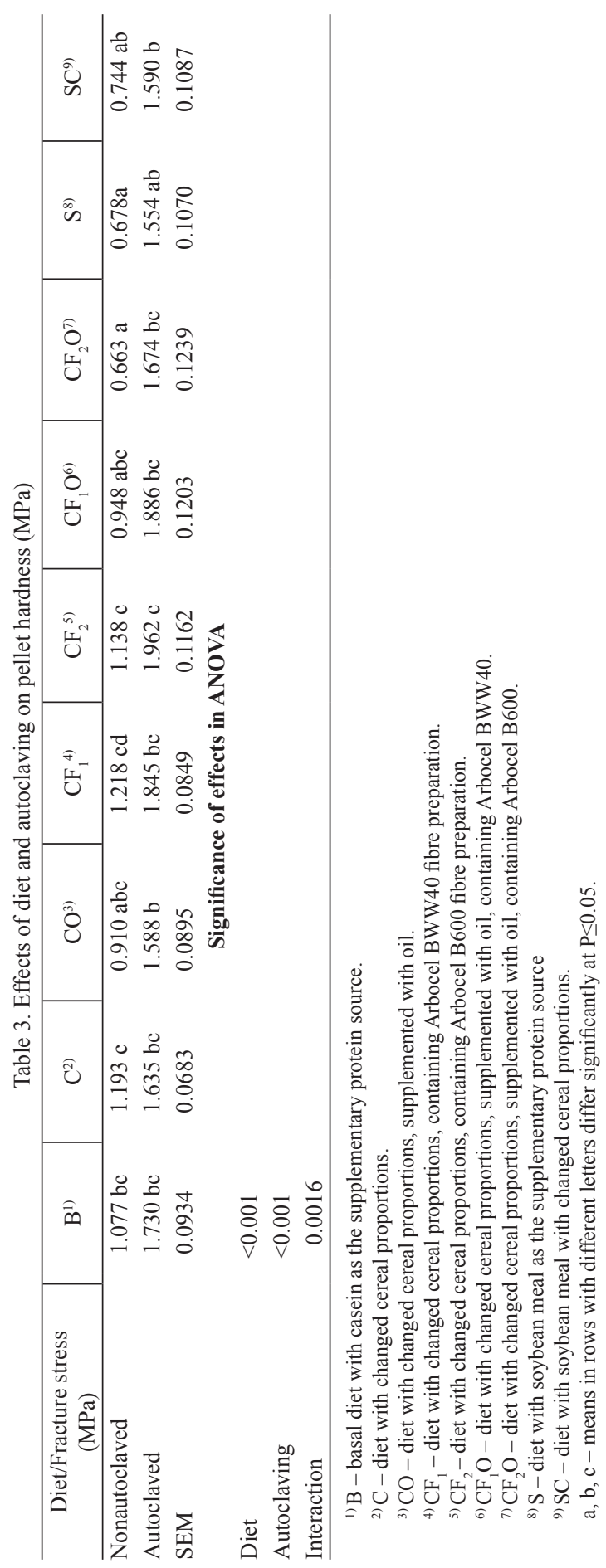




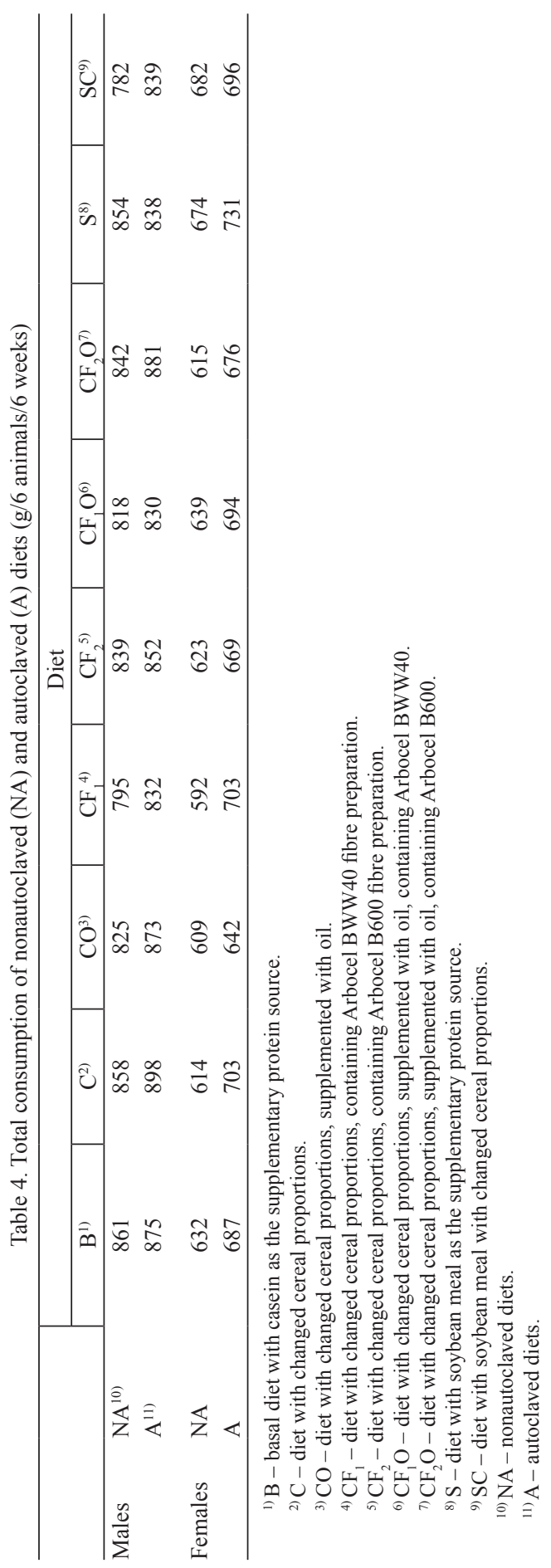




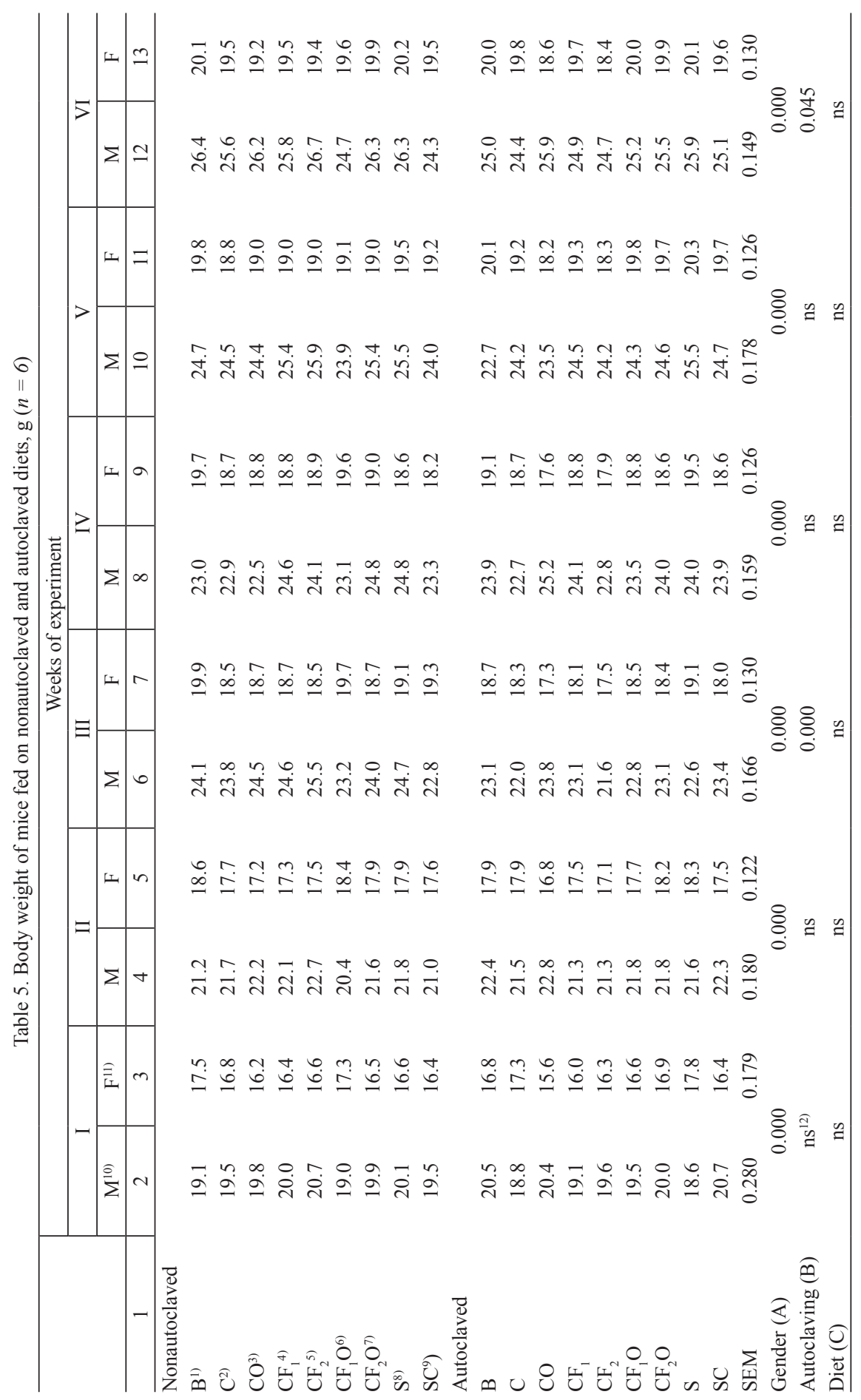




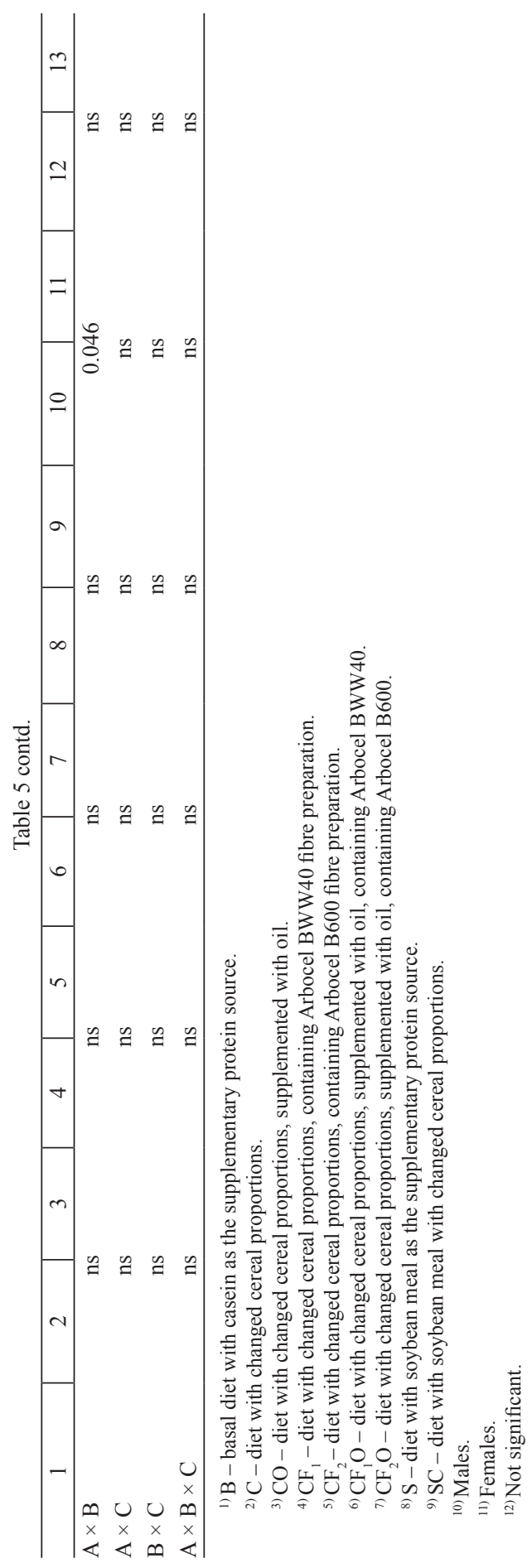


Analysis of regression demonstrated that pellet hardness (y) depends on amount of fat, fibre, starch, ash and phosphorus in the diet, according to the equation:

$$
y=-0.31 * f a t+0.68 * \text { fibre }-0.13 * \text { starch }+1.26 * \text { ash }-5.33 * \text { phosphorus }+2.37
$$

Pellet hardness is negatively correlated with fat, starch and phosphorus content and positively with fibre and ash content.

Results of the experiment on mice fed from 5th week of age on nonautoclaved and autoclaved diets, are summarized in Tables 4 and 5. Total consumption of autoclaved diets (except $\mathrm{S}$ diet in males) was greater than of nonautoclaved feeds, the difference being greater in females than in males. Body weight of mice was affected by gender as the males were consistently heavier than females. Ingredient composition of the diets had no effect on body weight, whereas autoclaving had a small negative effect in the $3 \mathrm{rd}$ and 6 th week of experiment only. In the 5th week a significant interaction between gender and sterilization was found, since body weight of males fed autoclaved diet was depressed by $0.6 \mathrm{~g}$ on average, while in females it was increased by $0.25 \mathrm{~g}$.

Table 6. Multiple regression analysis of factors responsible for variation in body weights (y) of mice

\begin{tabular}{|c|c|c|c|}
\hline $\begin{array}{l}\text { Week } \\
\text { of exp. }\end{array}$ & Multiple regression equation & $\mathrm{r}^{2}$ & P-value \\
\hline \multicolumn{4}{|c|}{ Males } \\
\hline 1 & $\mathrm{y}=-1.86 *$ fibre $-2.85 *$ ash $-0.62 *$ sugars +52.82 & 44.2 & 0.038 \\
\hline 2 & $\mathrm{y}=-2.03 *$ fibre $-2.83 *$ ash $-0.92 *$ sugars +52.07 & 67.1 & 0.001 \\
\hline 3 & $y=-2.33 *$ fibre $-5.00 *$ ash $+19.33 *$ phosphorus $+1.91 *$ gross energy +13.20 & 59.9 & 0.013 \\
\hline 4 & - & & - \\
\hline 5 & $y=63.15 *$ phytic phosphorus $+1.52 *$ gross energy -22.69 & 59.7 & 0.001 \\
\hline 6 & $\mathrm{y}=51.08 *$ phytic phosphorus $+1.99 *$ gross energy -27.54 & 46.9 & 0.009 \\
\hline \multicolumn{4}{|c|}{ Females } \\
\hline 1 & - & & - \\
\hline 2 & - & & - \\
\hline 3 & $\mathrm{y}=0.31 *$ fat $+9.40 *$ phosphorus +6.20 & 58.2 & 0.002 \\
\hline 4 & - & & - \\
\hline 5 & $\mathrm{y}=0.93 *$ protein $+12.43 *$ phosphorus $-0.61 *$ sugars -12.26 & 43.3 & 0.042 \\
\hline 6 & $\mathrm{y}=5.48 *$ phosphorus +13.78 & 23.7 & 0.040 \\
\hline
\end{tabular}

The relation of nutrient components in the experimental diets to mice growth was inconsistent (Table 6). During the first two weeks of the experiment growth of males was negatively correlated with fibre, ash and sugars while during the last two weeks positively with phytic phosphorus and gross energy content. Growth of female mice depended on nutrient content in a more irregular way, with no correlation during the first, second and fourth week of the experiment, while in the third, fifth and sixth week it was highly correlated with phosphorus content. 


\section{Discussion}

Our results concerning the effects of diet composition on the pellet hardness of nonautoclaved diets indicate the influence of type of protein source, the hardness of the casein containing diets being far greater than of diets containing soybean meal. According to Thomas et al. (1998), proteins may exert the adhesive forces and in feed manufacturing may act as binding agents between feed particles. It was shown that partial denaturation of protein during pelleting may positively affect the hardness of the feed pellets, which is greater when raw protein rather than denatured is processed (Wood, 1987). The protein supplements used in our experiment differ in their origin and have been subjected to different processing prior to pelleting, casein being probably more denatured than soybean meal due to a more complex treatment. It is therefore difficult to speculate on the mechanism of their effects on the observed differences of pellet hardness. According to Thomas et al. (1998), the pelleting qualities of extracted soybean meal are rated rather low but no comparable data for casein are available. It may be also hypothesized that physical properties of soybean meal and its probably greater porosity related to fibre contents, may be the main reason of smaller hardness of the pellets.

The change of the inclusion rate of cereals differing in their viscosity, i.e. partial substitution of maize for wheat, had no effect on pellet hardness. This finding contrasts with considerably lower pellet quality, including decrease of pellet hardness, of maize than wheat found by Thomas et al. (1998).

According to producers, all three preparations are natural cellulose fibres differing to some extent in fibre length and bulk density but it is not possible to tell whether their physical characteristics may be responsible for the observed different pellet properties after sterilization. As indicated by Thomas et al. (1998), the effect of insoluble plant fibre may be twofold. It may loosen pellet structure due to their stiffness and elasticity but it also may increase pellet hardness due to entangling and folding between different particles, which was confirmed by regression analysis. Water affects resilience of plant fibres thus it is possible that sterilization involving additional steam and heat treatment may have greater effect discerning the properties of two fibres than simple pelleting. Added fat is considered as a component deteriorating pellet hardness and pellet durability due to its hydrophobic and lubricating properties, which was also revealed by regression analysis. However, natural oils and waxes released from plant cell walls during processing, may have opposite effect (Thomas et al., 1998). In our experiment the effect of oil supplementation seemed to depend also on the type of fibre preparation. Both after pelleting and after autoclaving oil supplementation effect on pellet hardness was greater when added to diet $\mathrm{CF}_{2}$ with Arbocel B600 than to diets $\mathrm{C}$ or $\mathrm{CF}_{1}$ containing Vitacel or Arbocel BWW 40 , respectively. Pellet hardness depended also on the crude ash, total phosphorus and starch content, although the differences between diets in these nutrients content were of small magnitude. This finding may indicate an important interrelationship between dietary components during processing.

The conditions of autoclaving applied in this study do not restrict the acceptability of the diets by young animals. The greater feed intake of autoclaved than non- 
autoclaved diets may be due to the effect of their greater palatability and compensation for their slightly lower metabolizable energy concentration (unpublished). The relatively small differences in feed intake among the diets could not be confirmed statistically since feed intake was registered collectively (per cage).

The relationships between body weight of mice and nutrient content are difficult to explain. Younger male mice seem to be more sensitive to fibre and ash content than older animals. The effect on body weight may in fact result from pellet hardness, since young animals may have problems with feed consumption. The recommendations on the acceptable pellet hardness for laboratory animals are scarce. According to Ritskes-Hoitinga and Chwalibog (2003), the pellet hardness of one type of diet could vary between 4 and $50 \mathrm{kPa}$ and a value higher than $20 \mathrm{kPa}$ is considered as a problematic one. These values, however, are not comparable with those measured in our study, the discrepancy may be caused by possible differences in the methodology of hardness measurements. The reason for different response of females to nutrient content remains to be elucidated.

It may be concluded that pellet hardness is increased by autoclave sterilization at $121^{\circ} \mathrm{C}$ during 20 minutes and depends on fat, fibre, starch, ash and phosphorus content. Pellet hardness is affected by source of protein but not by cereal proportions. The effects of dietary modifications on pellet hardness seem to differ between the nonautoclaved and autoclaved diets: supplementation with oil tends to decrease pellet hardness of nonautoclaved but not of autoclaved diets, whereas type of fibre has no effect in nonautoclaved diet and tends to modify pellet hardness after autoclaving. An interaction of fibre type and oil supplement in autoclaved diets is postulated. Contrary to our earlier observations, autoclaving stimulates feed consumption in young mice in spite of increased pellet hardness and negatively affects body weight of mice, but to a very small extent and only in few periods.

\section{Acknowledgements}

The authors gratefully acknowledge Rettenmaier \& Sohne GmbH for providing fibre preparations.

\section{References}

A a r s e th K.A., S orens en M., S t o r e bakken T. (2006). Effects of red yeast inclusion in diets for salmonids and extrusion temperature on pellet tensile strength: Weibull analysis. Anim. Feed Sci. Technol., 126: 75-91.

Bielohuby M., Bodendorf K., Brandstetter H., Bidlingmaier M., Kienzle E. (2010). Predicting metabolisable energy in commercial rat diets: physiological fuel values may be misleading. Brit. J. Nutr., 103: 1525-1533.

B r o w n N.M., S e t c h e 11 K.D.R. (2001). Animal models impacted by phytoestrogens in commercial chow: implications for pathways influenced by hormones. Lab. Invest., 81: 735-747.

F e 11 J.T., N e w t o n J.M. (1970). Determination of tablet strength by the diametral-compression test. J. Pharm. Sci., 59: 688-691.

F or d D.J. (1976). The effect of methods of sterilization on the nutritive value of protein in a commercial rat diet. Brit. J. Nutr., 35: 267-276. 
Nicklas W., B aneux P., B oot R., Decelle T., Deeny A.A., Fumanelli M., Illgen-Wilcke B. (2002). Recommendations for the health monitoring of rodent and rabbit colonies in breeding and experimental units. Lab. Anim., 36: 20-42.

Ritskes-Hoitinga M., Chwalibog A. (2003). Nutrient requirements, experimental design, and feeding schedules in animal experimentation. In: Handbook of Laboratory Animal Science, 2nd ed., Hau J., Hoosier G.L. (eds). CRC Press, Boca Raton, pp. 281-310.

Sørensen M., Stjepanovic N., Romarheim O.H., Krekling T., Storebakken T. (2009). Soybean meal improves the physical quality of extruded fish feed. Anim. Feed. Sci. Technol., 149: 149-161.

Th o m a s M., v a n der Po el A.F.B. (1996). Physical quality of pelleted animal feed. 1. Criteria for pellet quality. Anim. Feed Sci. Technol., 61: 89-112.

Thomas M., van Zuilichem D.F.J., van der Poel A.F.B. (1997). Physical quality of pelleted animal feed. 2. Contribution of processes and its conditions. Anim. Feed Sci. Technol., 64: $73-192$.

Thomas M., van Vliet T., van der Poel A.F.B. (1998). Physical quality of pelleted animal feed. 3. Contribution of feedstuff components. Anim. Feed Sci. Technol., 70: 59-78.

W o o d J.F. (1987). The functional properties of feed raw materials and their effect on the production and quality of feed pellets. Anim. Feed Sci. Technol.,18: 1-17.

Received: 15 III 2013

Accepted: 6 IX 2013 